


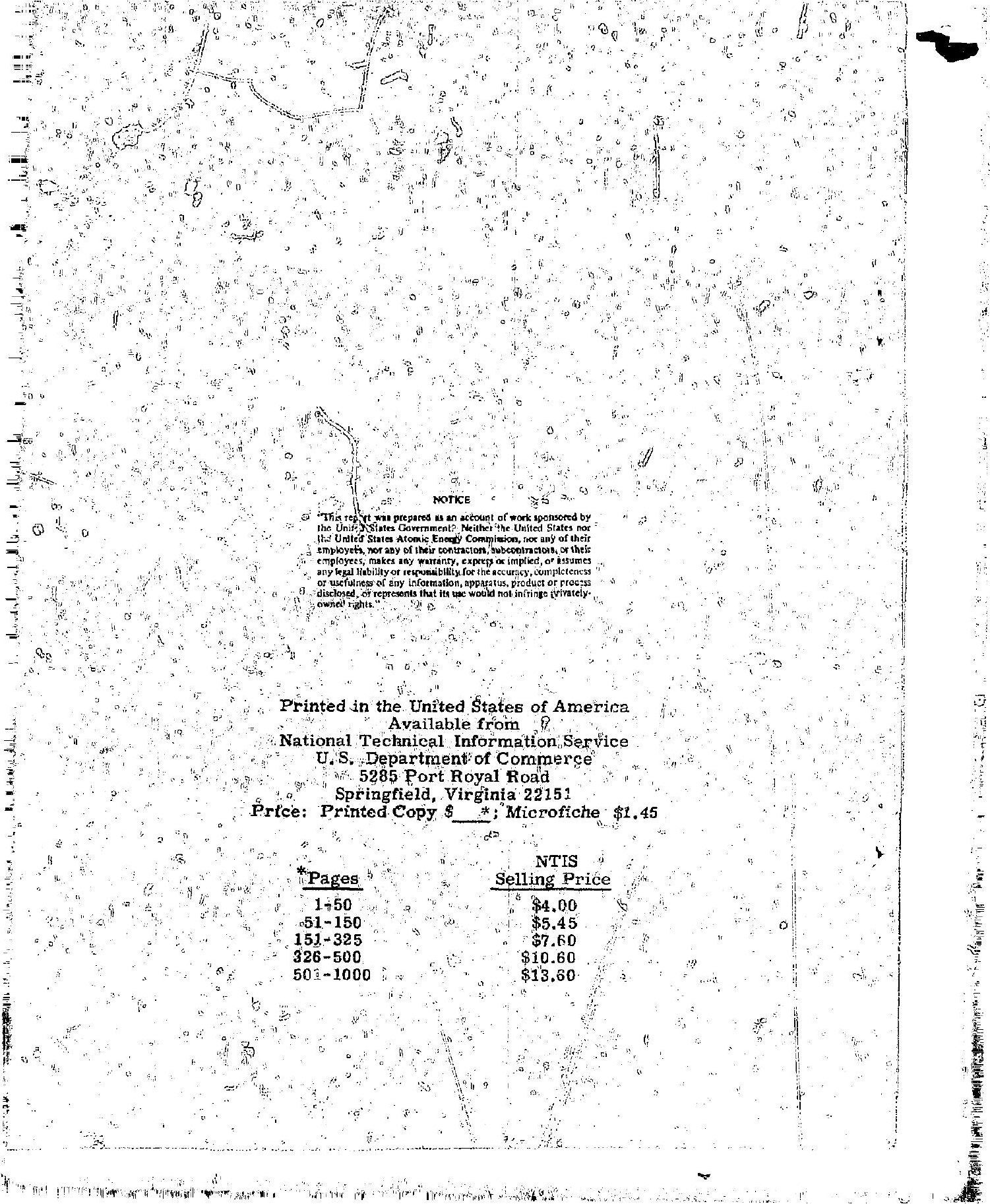




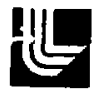

LAWFENCE LNERMOFE LAEORATORY

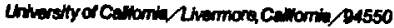

UCRL- 51634

\title{
A MODEL FOR TRITIUM AND DEUTERIUM TRANSPORT IN TARGETS FOR NEUTRON GENERATORS
}

\author{
C. M. Logan
}

MS. date: August 8, 1974

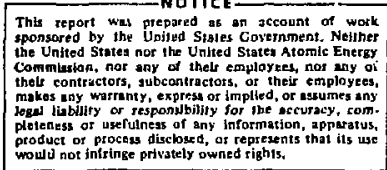

Thls report wes prepared $\mathrm{s} 5$ an sccount of work sponsored by the Unifud Sibles Cascmment. Nether Comited States nor the United States Atomic Energy thelt contractors, subcantractors, or their employes,

makes any warrent $y$, exprosu or implied, or essumes any

poge liability

product of proces disclose ds, as represents that its wa

would not infringe privately owned sighis. 


\title{
A MODEL FOR TRITIUM AND DEUTERIUM TRANSPORT IN TARGETS FOR NEUTRON GENERATORS
}

\begin{abstract}
The observed behavior of titanium tritide targets used for $14-\mathrm{MeV}$ neutron generation indicates that two mechanisms for tritium motion are active. A model is proposed based on thermally induced motion of tritium and deuterium in gamma

phase hydride plus a radiation-induced component dependent on the incident ion current density. The model describes the observed behavior and permits speculation regarding target life under different operating condltions.
\end{abstract}

\section{Introduction}

There is increasing need for intense sources of 14-MeV neutrons. Two major applications are for cancer therapy and for materials studies related to $D-T$ fusion reactors. Machines to generate these neutrons utt?ize the fusion of deuterium and tritium. Usually the tritiım is contained in some type of target while deuterium ions are accelerated and directed into the tritium-bearing target to produce the D-T fusion, atthough systems have been suggested which would accelerate the tritium instead. In order to achieve high flux densities in small samples, it is necessary to have as the neutron source a target design which tolerates intense ion beams of small diameter and permits sample placement near it.

The most successfui source of this type is the Lawrence Llvermore Laboratory's rotating target. In normal use, atomic deuterium inns are accelerated to $400 \mathrm{keV}$ and impinge on a rotating target.
The beam is typically less than $1 \mathrm{~cm}$ in diameter and contains about $15 \mathrm{~mA}$ of deuterons $(\sim 6 \mathrm{~kW}$ of beam power). This power is deposited in the front $3 \mu \mathrm{m}$ of target thickness, and the heat it produces is conducted to the backing and removed by a flow of cooling water over the back surface. The normal target has a $10-\mu \mathrm{m}$ $\left(4.5-\mathrm{mg} / \mathrm{cm}^{2}\right)$ vapor-deposited layer of titanium tritide on a copper alloy backing. The tritium content of a new taryet approaches 1.5 tritium atoms per titanium atom. Such targets contain a very high density of tritium atoms. A fully stoichiometric compound of $\mathrm{TiT}_{2}$ has a tritium atom density twice that of liquid tritium at $20^{\circ} \mathrm{K}$.

There are many innovative features of the cooling and rotating systems of the LLL neutron source which have been described elsewhere. ${ }^{1-4}$ In this paper I intend to describe the observed behavior of the target used in this source and other similar systems and to formulate a 
tritium-transport model which will explain the behavior and hopefully permit prediction of target performance under different operating conditions.

\section{The Target Environment}

The gas pressure at the front target surface (on the beam side) must be about $10^{-5}$ torr or less to permit beam transport to the target. Early proposals for solid targets assumed that the target temperature could not be permitted to exceed about $250^{\circ} \mathrm{C}$, and indeed for stationary, steady-state operation, target life is severely shortened by such temperatures. This target, because of its rotation at $1100 \mathrm{rpm}$, is subjected to a repeating cycle of a rapid temperature rise as it rotates through the beam, a rapid quench as the heat is conducted to the copper backing, and a gradual cooling as the target rotates around to the beam spot again. I have modeled the system in a one-dimensional trenslent heat transfer calculation using a finite difference code at LLL. For a given set of assumptions representative of the most severe operating conditions, the calculated temperature history ta displayed in Fig. 1. The peak temperature in the splke is seen to he considerably above the supposed limit, but does not stay there for very long. The calculation of the base temperature at the end of a cycle is uncertain because of uncertainty in the heat transfer to the water. The accuracy of the calculated temperature rise in the peak is limited mostly by uncertainty about the beam power density profile, and is expected to be representative of a current of $15 \mathrm{~mA}$ i:cident with full width at half maximum (FWHM) of $0.3 \mathrm{~cm}$.
The bombarding deuterons lose energy to electrons as they move through the target material and come to rest at a depth of about $1.7 \mathrm{mg} / \mathrm{cm}^{2}$. An estimate of the implanted distribution (before diffugion) Is shown in Fig. 2. As the deuterons move through the titanium-tritium layer, about one in $3 \times 10^{5}$ reacts with a tritium atom and creates a 14-MeV neutron. Some deuterons interact with titanium atoms and cause energetic recoils which then can cause further displaced atoms. This "radietion damage" from ion bombardment is most severe near the end of the deuteron range and will result in each titanium atom

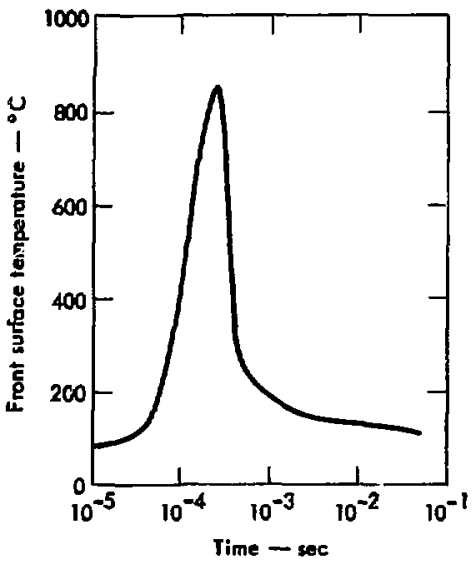

Ftg. 1. Calculated front-surface temperature va time for the LLL rotating target. 
being displaced severa] hundred times over the lifetinie of the target. I have written a computer code to calculate this damage rate from Rutherford scattering as a function of deuteron energy in titanium. From range-vi-energy data 5 it is then possible to determine the damage rate as a function of depth in the target. This is also given in Fig. 2. These values become uncertain at low energy because of energy spread in the moving deuterons. I have used energy loss and range data from Ref. 5 for metallic titanlum in this paper. A more precise approach would use weighted data for titanium and tritium, but this would make little difference for our purposes, and in view of the uncertainty in the data it is not appropriate.

Surface recession from ton sputtering should be insigniflcant. A sputtering ratio (atoms lost per incident ins) of about $10^{-3}$ would be expected ${ }^{6}$ and would remove about $0.01 \mathrm{mg} / \mathrm{cm}^{2}$ for each $\mathrm{mA}$ $\mathrm{hr} / \mathrm{cm}^{2}$ of exposure. While surface erosion is not an important consideration, sputtering would effectively remove surface oxide or carbon deposits and could change surface morphology.

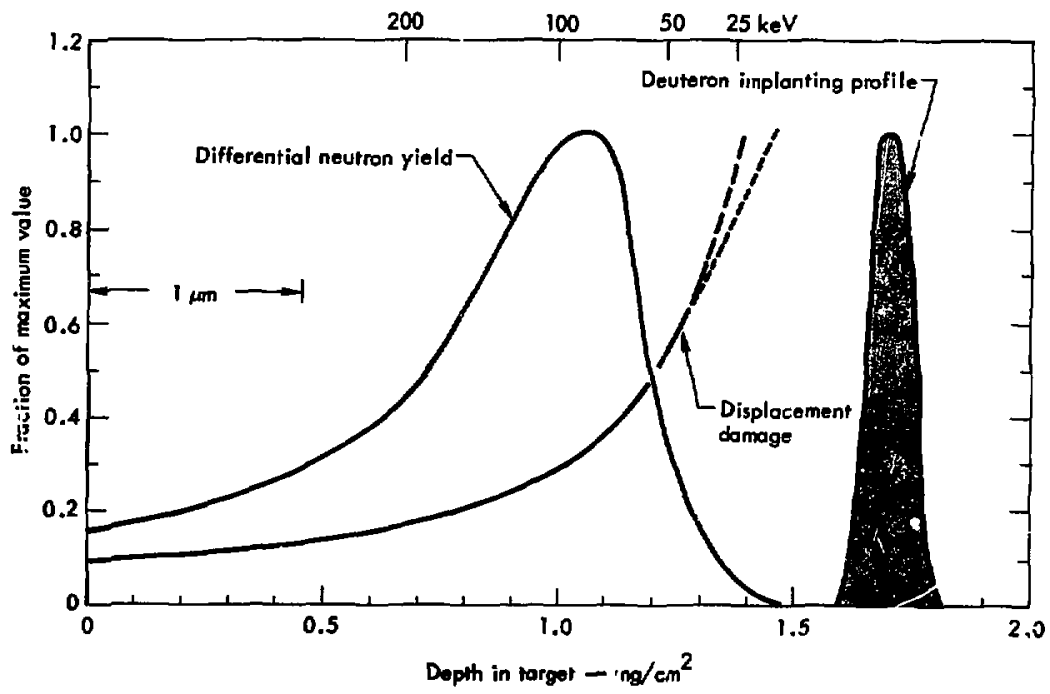

Fig. 2. Neutron yleld, displacement damage, and deuteron implantation vs depth in target, for 400-keV deuterons. 


\section{Neutron Yield vs Depth}

The variation of the $T(d, n) a$ reaction cross sectiol: $o(E)$ with deuteron energy is well known. ${ }^{7}$ The neutron yield $Y(E)$ in the target at any energy is given by

$$
Y(E)=K \frac{\sigma(E) \cdot N_{T}}{d E / d x} .
$$

where $E$ is the energy of the moving deuteron, $d E / d x$ is its rate of energy loss, and $N_{T}$ is the tritium density. For a con- stant tritium density, the relative neutron yleld as the deuteron moves through the layer is given in Fig. 2. Tritium deeper than about $1.5 \mathrm{mg} / \mathrm{cm}^{2}$ does not produce neutrons, and that contained near the front surface is relatively ineffective. This distribution to for a $\mathbf{4 0 0 - k e V ~ i n c i d e n t ~}$ energy. A lower incident energy would in effect remove the front portion of this distribution.

\section{Observations of Target Parameters and Target Behavior}

I know of no direct observations or measurements of tritium proflies, deuterium profiles, or ciensity profiles of used targets. The available evidence comes from observed neutron yields under various circumstances.

If we consider a titanium layer with 1.5 tritium atoms per titantum atom, there would be about $7 \times 10^{22}$ tritium atoms per $\mathrm{cm}^{3}$. Since the useful range is $3.3 \times 10^{-4} \mathrm{~cm}$, there are about $2.5 \times$ $10^{19}$ tritlum atome per $\mathrm{cm}^{2}$ avaliable over the useful range. If we use a targct until its yleld drops to about $70-80 \%$ of that of a new target we have implanted in it about $5.0 \mathrm{~mA}-\mathrm{hr} / \mathrm{cm}^{2}$ of deuterons, which is several times a many deuterium atoms as the number of tritium atons originally avallable.

The burnup of trittum from $D-T$ reactione is negligtble. About one atom in 5000 orer the first $1.5 \mathrm{mg} / \mathrm{cm}^{2}$ of target material is utllized. However, tritium is lost from the target, and observations of the accumulation in the vacuum pumping system indicate that between 0.1 and
0.2 of a tritium atom are emitted for each incident deuteron. ${ }^{2}$ There has been one psorly documented observation of the gas evolution from an operating target. ${ }^{8} \mathrm{~A}$ mass spectrograph indicated a nearly constant gas flow of molecular hydrogen. It was initially dominated by $T_{2}$, then changed to mixed DT, and finally was dominated by $D_{2}$ p zer the end of the viseful target life.

Careful observations of the Livermore gystem indicate a slight rise in neutron yield for a short time when starting up with a fresh target. This is followed by a period of fairly rapid decay and a second period with more slowly varying gleld. 4 Figure 3 is reproduced from Ref. 4. The referance to small and large radius applles to the terget. The target velocity is about a factor of two higher at the large, radius. This decay with two separate time constants has algo been observed at other laluratories ${ }^{9}$ for fixed (low-intensity: targets ubing lower bombarding energies.

Figure 4 (from Ref. 2) shows the neutron field for various bombarding 
energies for fresh and used target.;. The fresh target shows a yield consistent with uniform tritium concentration over the $1.5-\mathrm{mg} / \mathrm{cm}^{2}$ useful range. The measured yleld at 200-keV bombarding energy would be sens:tive to any tritium depletion near the front surface, and the measurements indicate that any surface layer containing no tritium must be less than $0.3 \mu \mathrm{m}$ thick. Other laboratories have also observed surface depletion in $0.1-\mu \mathrm{m}$ layers. ${ }^{10}$ After some use at 400 -keV bombarding energy, the target yield has decreased. If at this puint the bombarding energy is increased, the yield decreases further. After prolonged use at

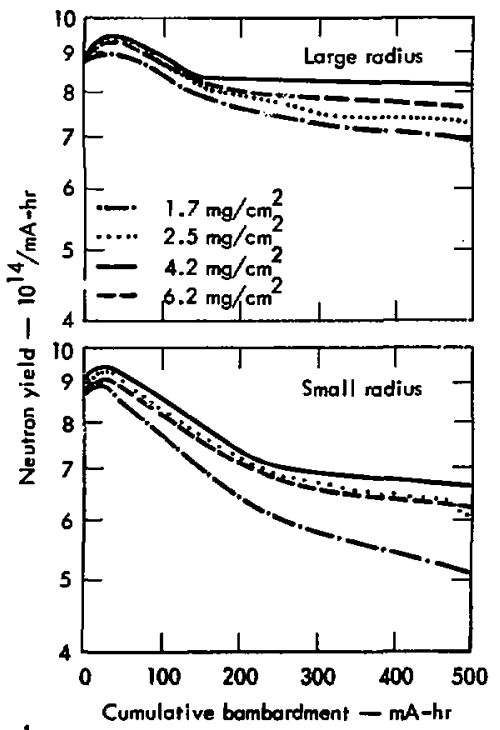

Fig. 3. Neutron yleld decay curves for various thicknt 38 es of the titanium tritide layer at the front of the target. Yield is plotted as a function of cumulative bombardment.

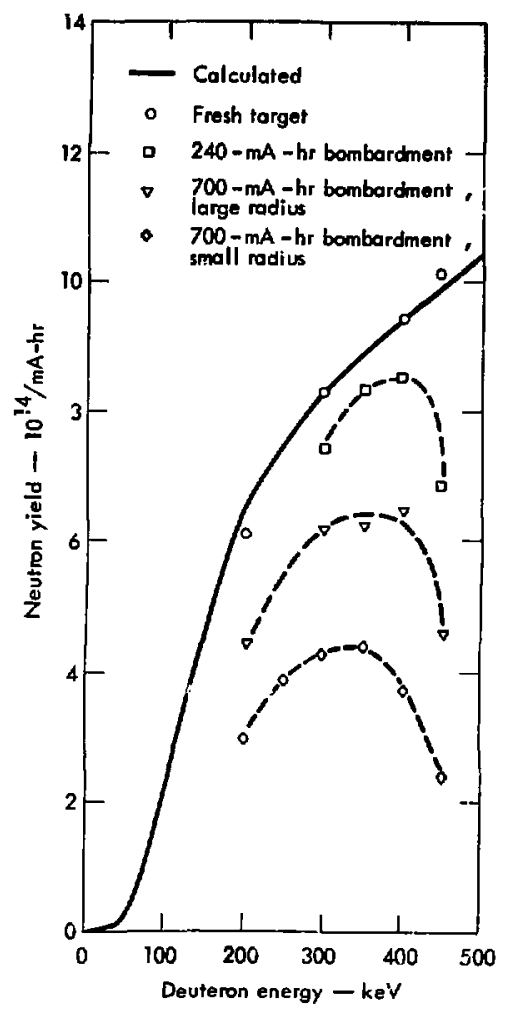

Fig. 4. Neutron yield vs deuteron energy for targets after various exposures to $400-k e V$ deuterons.

$400 \mathrm{keV}$ thls phenomenon is so pronounced that decreasing the bombarding energy actually increases the yigld. An estimate of tritium profiles which would account for this behavior is given in Fig. 5. This constant reduction factor for yield n.t 200 and $300 \mathrm{keV}$ is a strong indication that no steep gradientu exist in the first $1.0 \mathrm{mg} / \mathrm{cm}^{2}$ of target material, and the 


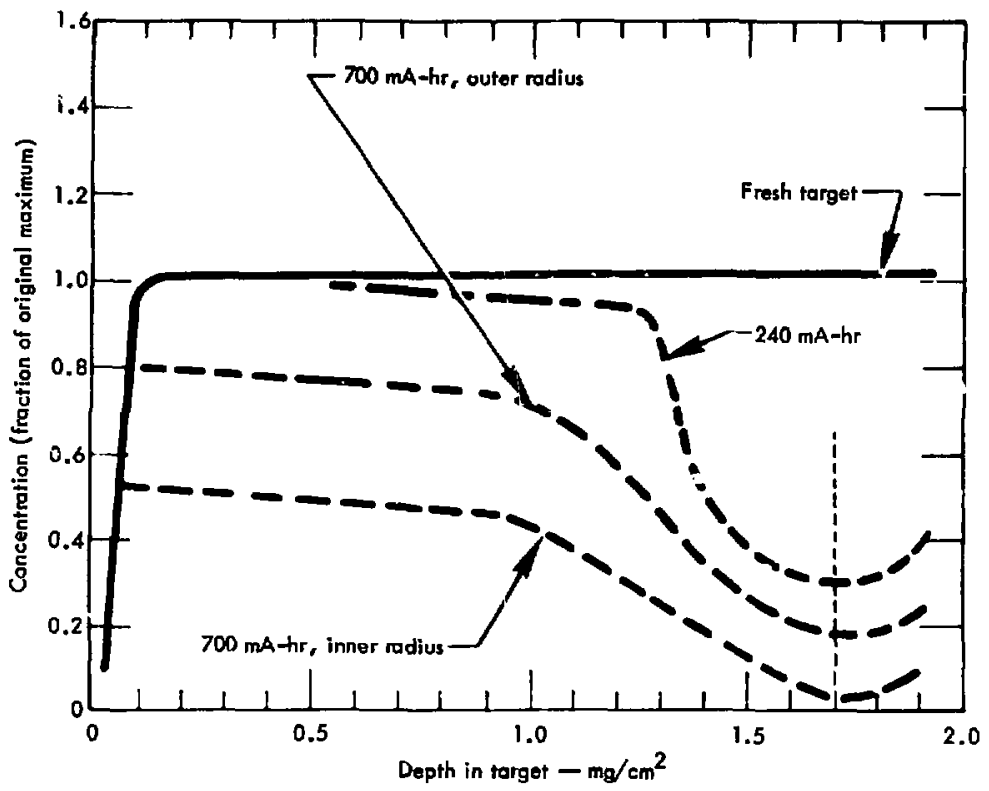

Fig. 5. Trittum concentration vs depth in target for various target use histories.

sharp loss of yield for $450-k e V$ deuterons indicates that a severe depletion uccurs between 1.0 and $1.5 \mathrm{mg} / \mathrm{cm}^{2}$ from the front surface.

Studies have been made $4,11,12$ on the effect cf the thickness of the titanium layer. There is little efiect on initial yield so long as the layer thickness is at least equa' to the deuteran range. However, the life of the target is improved by thicker titanium layers up to thicknesses about 2.5 times the deuteron range. Thicknesses greater than this decrease the useful target life.

Small static targets have been bombarded under various cooling conditions, 11,13 These targets experience a constant temperature while being bumbarded. They fall quickly at $250^{\circ} \mathrm{C}$, have an icceptable lifetirne at $115^{\circ} \mathrm{C}$, and a somewhat bet...r lifetime (decay rate reduced $\sim 30 \%$ ) when Freon-cooled to below room temperature. For the Livermore rotating target system, by contrast, cooling with shilled water z $2-$ sults :n no observable change in target life. 14

Some attempts have been made to run targets of this ty s: with mixed bea.ns of atomic and diatomic ions. The neutron yield drops very rapidly under these conditions. ${ }^{14}$ No effect on tarect life is observed from the elimination of oil diffusion pumping, ${ }^{14}$ indicating that surface 
carbon depositg are not present or do not influence target life.

When targate are made with thicker tifantum layers, the tritium loading that can be achleved increases and in some cases approaches stolchlometry for layers thicker than $10 \mathrm{mg} / \mathrm{cm}^{2}$ (Refs, 15 and 18).

\section{The Titanium-Hydrogen Syatem}

Most of the literature on the titaniumhydrogen system has dealt with low hydro. gen concentrations. The phase diagram shows that for equillurium below about $300^{\circ} \mathrm{C}$ two phases exist. The alpha phase of titanium is hexagonal-close-packed. The solubllity of hydrogen in the alpha phase is at jut 0.0005 atom fraction at room temperature ${ }^{17}$ and reaches a maxlmum of approximately 0.08 near $300^{\circ} \mathrm{C}$. The gemma phase compound $\mathrm{THH}_{2}$ has a face-centered-cubic fluorite-type structure and exists with a composition as low as
50-60\% hydroc-n. No appreciable difference is known to exist for the titaniumdeuterium or titanium-tritlum systems, 6,18

Impurttles have heen observed to have dramatic effecte on phase boundarles anc solubtlities. Oxide layers are apparently formidable barriers to hydrogen diffusion. 18

Since the temperature exceeds $300^{\circ} \mathrm{C}$ for only very short times and interesting tritium concentrations are greater ihan $30 \%$, we are probably always dealing with a mixture of alpha and gamme phases or pure garima.

\section{A Proposed Mechanism for Target Degradation}

The evolution of tritium and deuterium from targets of this type cannot be surfaceItrited. One would not expect a surface layer (such as oxide) to survive the displacements an sputteing caued by the deuterons. If a surface barrier existed with relatively easy Internal diffusion, no appreciable hydrogen concentration gradients could exist. We observe that the implanted deuterium must move rather slowly and that it displaces trittum at the implantation depth.

The loss of tritium is partially thermally activated. The rate of target decay is dependent on temperature for other conditions being, equal, but targets also show yield drop when used at room temper- ature. These targets can be stored for prolonged pertods at room temperature without yleld loss, so no appreciable thermal degradation occurs at that temperature. Part of the $t_{2}$ ttlum loss must occur from a mechanism lice radiaitonenhanced (nonthermal) difífusion.

There is a strong experimental and theoretical basis ${ }^{19}$ for describing the jump frequency of a hydrogeid atom in the gamma phase by the expression

$$
v=\frac{1}{2}(2-x)\left(36 \times 10^{12}\right) \exp (-U . .27 / \mathrm{kT}),
$$

where $\mathrm{X}$ is the number of tritium atcms per titanium atom. The hydrogen atoms occupy the tetrahedral sites in the fcc 
lattice. When $X=\varepsilon$ all the tetrahedral sites are occupied. Stnce no thermally created vacancies are present the jump frequency is prof-:rtional to the fraction of vacant sites, $\frac{1}{2}(2-x)$.

I suggest that the incident deuterons can modify the jump frequency in two ways: 1) The collision cascades create vacancies not related to the tritiun content so that the concentration of vacant sites also depends on the average incident deuteron current density ${ }^{\prime} d^{*}$ 2) The kinetic energy of the cascade also causes "jumps" which are not thermally activated and which have a frequency proportional to current density. With these tw, considerations the expression for jump frequency becomes

$$
\begin{aligned}
v=\left[\frac{1}{2}(2-X)+K_{1} \rho_{d}\right]\left(36 \times 10^{12}\right) \\
\quad \times \exp (-0.507 / k T)+K_{2} \rho_{d}
\end{aligned}
$$

Since for the cases of interest $X$ never approaches 2 and the lifetime of a collision vacancy is short, $K_{1} \rho_{d}<\frac{1}{2}(2-X)$ and we can neglect the contribution from the $K_{1} \rho_{d}$ term.

A vefy rough estimate of the $K_{2} \rho_{d}$ term can be made frcin several observations. These targets can be soldered at $100^{\circ} \mathrm{C}$ without serious damage, ${ }^{13}$ yet they lose tritium when used at $-20^{\circ} \mathrm{C}$. The average current density on the LLL rotating target is similar to that used on fixced targets at about $30 \mu \mathrm{A} / \mathrm{cm}^{2}$. A very rough guess is that at a temperature of $127^{\circ} \mathrm{C}$ i the thermal jump frequency and the deutero: $:$ iduced jump frequency are equal. If we let $X=1.2, p_{d}=30 \mu \mathrm{A} / \mathrm{cm}^{2}$, $T=400^{\circ} \mathrm{K}$, and evaluate $\mathrm{Eq}$. (3) for equal contributions, $\mathrm{K}_{2}=2 \times 10^{5}$ (jumps/sec) $\left(\mathrm{A} / \mathrm{cm}^{2}\right)$. This value siems very large when compared to the energy deposition. If all the energy of eech $400-k e V$ deuteron were transferred to tritons requirin'; $1 / 2$ eV to jump, we would have $8 \times 10^{5}$ jumps Induced by each incident deuteron. Sir:ce $1 \mu \mathrm{A} / \mathrm{cm}^{2}$ ta $6 \times 10^{12}$ deuterons $/ \mathrm{cm}^{2}$-sec and there are $3 \times 10^{19} \mathrm{tritons} / \mathrm{cm}^{2}$ over the deuteron range, about 0.2 jump/sec (for each atom) would be induced for each $\mu \mathrm{A} / \mathrm{cm}^{2}$ of deuterons - only one millionth of the value $\mathrm{K}_{2}=2 \times 10^{5}$ that was ertimated above by Eq. (3). Since vory small energy tranafers may cause jumps, and since a 1/2-eV atom may jump many times, this large value is not energetically imposstble. It may be this high because some of the energy last to the electrons in the compound effectively reduces the activation energy for motion of tritium.

The expression for jump frequency is then

$$
\begin{aligned}
v=1.5 \times 10^{13} & \exp (-0.507 / \mathrm{kT}) \\
& +2 \times 10^{5} \rho_{\mathrm{d}} .
\end{aligned}
$$

This is plotted vs $1 / T$ in Fig. 6 for $\rho_{d}=$ $30 \mu \mathrm{A} / \mathrm{cm}^{2}$.

We can see from this that for this model there is little point in attempting to lower the target temperature below $80^{\circ} \mathrm{C}$ unless the purpose is to limit the temperature excursion in the peak or to operate in a particular temperature range : equired by the cooling fluid used.

The diffusion coefficient is proportional to the jump frequency so that an appropriate measure of diffusion-induced motion is $(\nu \mathrm{t})^{1 / \mathrm{m}}$, where $t \mathrm{i}$ is the time and $n$ is between 1 and 2. For a given temperature history it is then possible to define an average value of $(v t)^{1 / n}$ called $\Delta$ which is 


$$
\Delta \equiv \frac{\int(v t d t)^{1 / n}}{\int(d t)^{1 / n}} .
$$

This value is the appropriate figure of merit for a given temperature cycle. For simple time cycles we can evaluat? this expression and we see that for $n=2,10^{-3}$ sec at $1000^{\circ} \mathrm{K}$ causes the same diffusioncontrolled motion as $4 \mathrm{sec}$ at $400^{\circ} \mathrm{K}$. More complicated cycles require computer evaluation.

The value of $n$ depends on the way concentration gradients change. For a "diffusion couple" where the concentration is Initially discontinuous, the appropriate value for $\mathrm{n}$ is 2. For steady-state equillbrium flow (constant gradients) the flux is proportional to $v t$ and $n$ should be 1 .

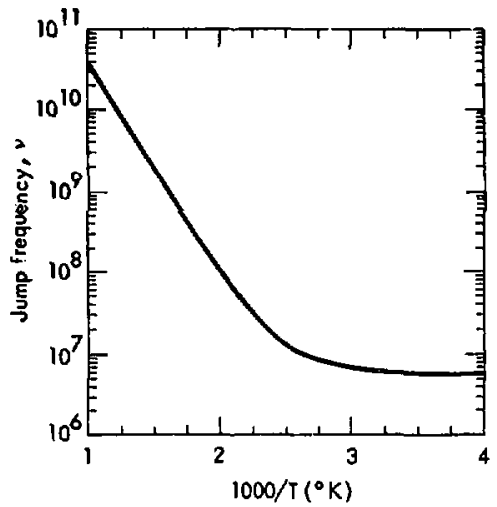

Fig. 6. Jump frequency of a tritium atom as a function of inverse temperature.

\section{Discussion}

There is a widespread impression that tritium in these targets diffuses forward from regions beyond the range into the useful part of the target material. $0^{3,911}$ The evidence cited for this is that lowest decay rates are observed when the tritiated layer thickness is about 2.5 times the deuteron range.

I believe, however, that such resupply do:s not occur in any significant amounts and that tritium in the target beyond the deuteron range is probably still there when the target is discarded.

Deuterons are implanted at about 1.7 $\mathrm{mg} / \mathrm{cm}^{2}$ depth with a spread of only about $0.1 \mathrm{mg} / \mathrm{cm}^{2}$ (for $400-\mathrm{keV}$ incident energy), so in a very short time there is an enormous hydrogen concentration peak at this depth. We have shown that this large drivIng force does drive tritlum from this region toward the forward part of the target, which results in the initial small increase in neutron yisld. Tritium also will be driven toward the back of the target, and in order for this tritium to resupply the front regions it will have to diffuse up a very large concentration gradient. But this cannot occur. Thus It appears that the region in the target beyord the deuteron range improves target life by serving as a dump for excess deuterium, thereby reducing the concentration gradient which drives tritium toward the front surface. If a target is used with the backing material just beyond the deuteron range, the deuterium plles up at the interface, doubles the concentration gradient, and results in rapid target deterioration. The oxide at the interface is a very effective diffusion barrier, and 
the soiubllity of hydrogen in the copper matrix is about $10^{-6}$ at $700^{\circ} \mathrm{K} .^{20}$ If on the other hand the titanlum tritile layer is very thick, it increaseg the tirget temiperature because of its low thermal conductivity $(-4 \%$ that of copper), and target life is again shortened.

The decrease in target decay rate after some usage is usually ascribed to the loss of all the tritium that is not "bound" in the delta phase. The very low solubility of hydrogen in the alpha phase obviously precludes this explanation, since losing all of the "dissolved" tritlum would not result in an observable yleld urop. I belleve the correct explanation for the observed behavior is the gradual achieving of equilibrium concentration gradients, so that the effective value of the parameter $1 / \mathrm{h}$ in Eq. 5 changes from $1 / 2$ to 1 .

This discussion has asaumed that hydrogen motion in gamma-phase titanium tritide is the limiting mechanisra for target behavior. Since some alpha-phase titanium metal may be present it may influence the model. Hydrogen diffuses much more readily in alpha titanium than in the ganisia phase. ${ }^{21}$ Further, hydrogen solubllity is very low in the alpha phase so that no appreciable deuterium or tritlum inventory resides there. I believe that the presence of the alpha phase does not compromise the validity of this model, but it may make it impossible to calculate the actual concentrations gresent in a target. A conthuous ulpha matrix would serve as a "pipeline" for deuterium and tritium which had egcaped from th gamma phase. Thlo may create a mechanism for discharging deuterium from deep in the target without "flushing out " the trittium in the useful ragion.

\section{Acknowledgments. I wish to acknow-} ledge many fruitful discussions with $R$ ex Booth and Henry H. Barschall. I am grateful to John D. Anderson for his support. 


\section{References}

1. R. Booth, Nucl. Instrum, Meth. 59, 131 (1968).

2. R. Booth and H, H. Barschall, Nucl. Instrum, Meth. 99, 1 (1972).

3. R. Booth, H. H. Barschall, and E. Goldberg, IEEE Trans. Nucl. Sci. NS-20(3), 472 (1973).

4. R. Booth and H. H. Barschall, Proc. AEC Blology and Medicine Workshop, June 17, 1972, Las Vegas, Nevada (see also UCRL-73975).

5. L. C. Northcliff and R. F. Schilling, Nucl.Data, Sec. A ?, Nos, 3 and 4 (1970).

6. M. Kaminsky, Atomic and Ionic Impact Phenomena on Metal Surfaces (Acaomic Press, New York, 1965).

7. See for example J. B. Marion and J. L. Fowler. Fast Neutron Physlcs Part 1 (Interscience, New York, 1960).

8. R. Booth, Lawrence Livermore Laboratory, personal communication (1973).

9. D. M. Bibby, G. Oldham, and A. R. Ware, Nucl. Energy 11, 68 (1970).

10. E. M. Gunnersen and G. James, Nucl. Instrum, Meth. $\underline{8}, 173$ (1960).

11. M. Guillaume, G. Delfiore, G. Weber, and M. Cuypers, Nucl. Instrum. Meth. 92, 571 (1971).

12. S. M. Kabir, Nucl. Instrum. Meth. 109, 533 (1.973).

13. J. Rethmeier and D. R. Van der Meulen, Nucl. Instrum. Meth. 24, 349 (1963).

14. R. Booth and H. H. Barschall, Lawrence Livermore Labotatory, personal communicalion $(19 ; 3)$.

15. L. C. Beavis and C. J. Miglionico, J. Less-Common Metals 27, 201 (1972).

16. L. C. Beatris, J. Less-Common Metals 19, 315 (1969).

17. 1. I. Phillips, P. Poole, and L. L. Shreir, Corrosion Sci. 12, 855 (1972).

18. W. M. Mueller, J. P. Blackledge, and G. G. Libowitz, Mntal Hydrides (Academic Press, New York, 1968).

19. C. Korn and D. Zariir, J. Phys, Chem. Solids 34, 725 (1973).

20. R. B. McLellan, J. Phys. Chem, Solids 34, 1137 (1973).

21. J. H. Swisher, Diff usion Model for the Thermal Decomposition of $\mathrm{TiH}_{2}$, Sandia Laboratories, Livermore, Rept. SCL-RR-720059 (1972). 